\title{
Vascular resections in pancreatic cancer
}

\author{
Thilo Hackert • Markus W. Büchler
}

Published online: 25 June 2010

(C) Springer-Verlag 2010

\section{Background}

The most important factor to improve the poor prognosis of patients with pancreatic adenocarcinoma (PDAC) is to achieve a radical surgical resection followed by adjuvant chemotherapy $[1,2]$. The question to which extent surgical resection is reasonable especially in advanced tumors has been controversy discussion within the last two decades $[3,4]$. In the meantime, several studies with high scientific quality have clarified at least parts of this problem that has led to changes in the sometimes fatalistic attitude which clinicians even in surgical departments face this tumor entity with.

\section{Venous resections}

Initially described in the 1970s, resection of the portal vein or the superior mesenteric vein have gained wide acceptance in centers around the world. The resection with a direct anastomosis or the interposition of a graft can be performed safely, which has been demonstrated in large series that showed surgical morbidity and mortality rates comparable to pancreatic head resections without vascular involvement [5-8]. In addition, oncological outcome in patients with vein resections has been shown to be similar without increased rates of local or systemic failure [9]. Owing to this observation, an involvement of the mesenteric or portal vein seems to be rather a consequence of the tumor located close to these structures than a reflection of a

T. Hackert · M. W. Büchler ( $\square)$

Department of Surgery, University of Heidelberg, Im Neuenheimer Feld 110, 69120 Heidelberg, Germany

e-mail: Markus_Buechler@med.uni-heidelberg.de uncommonly aggressive tumor biology. Venous resections should therefore be performed in a routine setting to achieve a complete removal of the tumor, which has meanwhile been explicitly stated in national guidelines, such as the German consensus publication of 2007 [10].

\section{Arterial resections}

The resection of the celiac axis or the superior mesenteric artery has been performed since the 1970s in selected patients, but is still regarded as an extraordinary approach in PDAC surgery. If the superior mesenteric artery is involved in the tumor process, this is a general exclusion criterion for resection and has only been reported in few patients. In contrast, tumor adherence or infiltration along the celiac axis must not be considered as generally irresectable [11-13]. In selected patients, the celiac trunk might be resected down to its aortal orifice in Whipple as well as in left resection or total pancreatectomies [11, 12]. As long as the proper hepatic artery can be preserved, a reconstruction is possible. Restoration of the hepatic perfusion must be ensured by re-anastomosing the proper or common hepatic artery. It needs to be mentioned that there are no larger patient series on arterial resections in pancreatic surgery. Therefore, this procedure can be carried out safely in experienced hands, but is not based on highquality scientific data and outcome studies so far [14-16].

\section{Combined vascular resections}

Resection of both, the portal vein and the celiac axis or mesenteric artery is-comparable to arterial resections alone-not yet a standard procedure and has only be 
performed in a small number of patients. It may be an individual option for selected patients that are regarded suitable in terms of age and co-morbidities. However, its oncological value has not been proven in larger series, a topic that could be addressed in the nearer future.

\section{Vascular resection in multivisceral approaches}

The resection of adjacent organs during PDAC surgery is an established procedure to achieve a radical tumor removal $[6,7,17]$. Although multivisceral resection is associated with an increased morbidity, perioperative mortality and long-term survival is not increased in these patients [17]. In approximately $20 \%$ of the patients, multivisceral resection is performed together with portal or superior mesenteric vein resections. This additional procedure does not increase the risk for complications and should, therefore, be performed in patients qualifying for an extended approach of complete tumor removal.

In conclusion, venous resection during surgery for pancreatic cancer can be regarded as a standard procedure in experienced hands, which has been generally accepted and is today part of national guidelines, which underlines the importance and binding character of this approach, which can also be recommended during multivisceral procedures. Arterial resections are technically safe, but still need to be evaluated by high-power clinical studies. They can be an individual option, especially in young patients to achieve a radical surgical resection.

More extended approaches such as combined vascular resection are not yet based on sufficient scientific evidence although they are carried out with acceptable surgical complication rates. Ongoing studies will provide data to underline or disprove these concepts. The results can be expected in the near future and give new input to the discussion on radical PDAC surgery.

Conflict of interest None.

\section{References}

1. Wagner M, Redaelli C, Lietz M et al (2005) Curative resection is the single most important factor determining outcome in patients with pancreatic adenocarcinoma. Br J Surg 91:586-594
2. Neoptolemos JP, Stocken DD, Friess H et al (2004) A randomized trial of chemoradiotherapy and chemotherapy after resection of pancreatic cancer. N Engl J Med 350:1200-1210

3. Nakao A, Takeda S, Inoue S et al (2006) Indications and techniques of extended resection for pancreatic cancer. World J Surg 30:976-982

4. Hartel M, Wente MN, Di Sebastiano P et al (2004) The role of extended resection in pancreatic adenocarcinoma: is there good evidence-based justification? Pancreatology 4:561-566 (review)

5. Weitz J, Kienle P, Schmidt J et al (2007) Portal vein resection for advanced pancreatic head cancer. J Am Coll Surg 204:712-716

6. Sasson A, Hoffmann J, Ross E et al (2002) En bloc resection for locally advanced cancer of the pancreas: is it worthwhile? J Gastrointest Surg 6:147-158.51

7. Shoup M, Conlon K et al (2003) Is extended resection for adenocarcinoma of the body or tail of the pancreas justified? J Gastrointest Surg 7:946-952

8. Yeo CJ, Cameron JL, Sohn TA et al (1997) Six hundred fifty consecutive pancreaticoduodenectomies in the 1990s: pathology, complications, and outcomes. Ann Surg 226:248-257

9. Müller SA, Hartel M, Mehrabi A et al (2009) Vascular resection in pancreatic cancer surgery: survival determinants. J Gastrointest Surg 13:784-792

10. Adler G, Seufferlein T, Bischoff SC et al (2007) S3-Guidelines "Exocrine pancreatic cancer" 2007. Z Gastroenterol 45:487-523

11. Settmacher U, Langrehr J, Husmann I et al (2004) Reconstruction of visceral arteries with homografts in excision of the pancreas. Chirurg 75:1199-1206

12. Martin RC 2nd, Scoggins CR, Egnatashvili V et al (2009) Arterial and venous resection for pancreatic adenocarcinoma: operative and long-term outcomes. Arch Surg 144:154-159

13. Yekebas EF, Bogoevski D, Cataldegirmen G et al (2008) En bloc vascular resection for locally advanced pancreatic malignancies infiltrating major blood vessels: perioperative outcome and longterm survival in 136 patients. Ann Surg 247:300-309

14. Li B, Chen F, Ge X et al (2004) Pancreaticoduodenectomy with vascular reconstruction in treating carcinoma of the pancreatic head. Hepatobiliary Pancreat Dis Int 3:612-615

15. Amano H, Miura F, Toyota N et al (2009) Is pancreatectomy with arterial reconstruction a safe and useful procedure for locally advanced pancreatic cancer? J Hepatobiliary Pancreat Surg 16:850-857

16. Kanda M, Fujii T, Sahin TT et al (2010) Invasion of the splenic artery is a crucial prognostic factor in carcinoma of the body and tail of the pancreas. Ann Surg 251:483-487

17. Hartwig W, Hackert T, Hinz U et al (2009) Multivisceral resection for pancreatic malignancies: risk-analysis and long-term outcome. Ann Surg 250:81-87 